\title{
Role of basalt dust in the formation of the modified gypsum structure
}

\author{
Victoria Petropavlovskaya ${ }^{1, *}$, Maria Zavadko', Kirill Petropavlovskii ${ }^{2}$, Aleksandr \\ Buryanov $^{2}$, Tatiana Novichenkova ${ }^{1}$ and Andrey Pustovgar ${ }^{2}$ \\ ${ }^{1}$ Tver State Technical University, Tver, 170026, Russia \\ ${ }^{2}$ Moscow State University of Civil Engineering, Yaroslavskoe shosse, 26, Moscow, 129337, Russia
}

\begin{abstract}
Waste disposal in the production of building materials and the organization of waste-free technological processes require a large amount of multilateral research. The application of basalt dust in the production of gypsum materials has been little studied. The paper investigated the effect of basalt dust - waste production of basalt fibers, on the working mixtures and the properties of hemihydrate of calcium sulfate paste (standard consistency, setting time of gypsum dough, water absorption of the resulting gypsum stone). It is known that the addition of basalt waste has a positive effect on strength, but there is no data on its effect on the rheological properties of gypsum mixtures. It was revealed that the introduction of basalt dust into the composition of the gypsum composite contributes to the change of the plaster mix rheology and of the properties of the gypsum structure. This must be taken into account when selecting optimized formulations of working mixtures on the hemihydrate of calcium sulfate.
\end{abstract}

\section{Introduction}

The use of industrial waste in the production of building materials is of great interest and has been actively practiced since the end of the XIX century. To date, scientists have successfully found application to many industrial wastes in the construction industry, which contributed not only to improving the characteristics of the materials obtained, but also to reducing their cost. This approach allows us to make high-quality building materials not only affordable for a wide range of consumers, but also to save valuable raw materials.

However, at the moment, for many categories of waste, the possibility of utilization in real production has not been found. These wastes include basalt fiber production wastes.

The basalt fibers themselves are well established as a reinforcing material and are widely used in various industries [1]. Their production takes place in several stages: crushing of basalt, melting of basalt crumb in smelting furnaces and pulling out continuous fiber. The fiber can later be used as a finished product or knit into fabrics, mats, nets [2].

However, after crushing the rock and in the process of obtaining the basalt fiber itself, a huge amount of waste remains that are not used, thereby polluting the environment and increasing the costs of basalt production. Therefore, many scientists are interested in the implementation of basalt waste as a component of building materials [3, 4].

\footnotetext{
* Corresponding author: victoriapetrop@gmail.com
} 
For example, D. Yu. Aleksandrov in [5] studied the possibility of using waste basalt fibers in the road area, provides recommendations for improving the technology of preparation of dispersion-reinforced asphalt concrete. The authors of [6] found that the introduction of basalt powder in a cement binder in an amount of $10 \%$ helps to increase its strength. In the works [7-8], the cement mortar was modified with basalt powder in the amount of 10,20 and $30 \%$ by weight of cement, the authors noted significant savings in cement, with constant strength indicators. N. A. Eroshkina in [9] revealed that geopolymer binder based on basalt has a rather high water resistance coefficient and low water absorption. And the authors [10-11] proposed the option of disposal of basalt wastes by using them as a component of concrete. There is a decrease in their deformable indicators.

As the review of the literature shows, the use of products of basalt production, including its waste, has not been sufficiently studied precisely in gypsum binders and is of great practical interest.

The authors of this work have already carried out a number of studies confirming not only the possibility, but the effectiveness of the use of basalt dust in gypsum composites, it has been noted to have a positive effect on the strength characteristics of the gypsum stone obtained [12-15].

In the present work, studies of the effect of basalt dust on such properties of gypsum composites as standard consistency, setting time and water absorption are presented.

\section{Experimental}

The main component in the work was applied gypsum binder brand G-16 Samara gypsum plant, which had a water requirement of 35-40\%, the beginning of setting - no earlier than 4-5 minutes, the end of setting - no later than 20 minutes, the compressive strength - 16 $\mathrm{MPa}$, at bending - 6-7 MPa.

As an additive in the composition of the gypsum composite was also used waste industrial basalt dust.

When determining the standard consistency of the gypsum paste, its setting time, as well as the water absorption of the obtained gypsum stone, the content of basalt dust varied in the range from 8 to $12 \%$ of the weight of the binder, characteristics were also determined for a clean, additive-free gypsum binder.

To determine the standard consistency (normal thickness), a cylinder of stainless steel $100 \mathrm{~mm}$ high and $5 \mathrm{~mm}$ in diameter (Suttard viscometer) was used, according to GOST 23789 (Fig. 1). The standard consistency was taken as the ratio of the mass of water to the mass of the gypsum binder in grams of such a paste, the diameter of which, when the standard cylinder was raised, was $180 \mathrm{~mm}$.

To determine the setting time, gypsum paste of normal consistency was used, Vica device was used (Fig. 2). The beginning of setting was taken as the number of minutes elapsed from the moment the binder was added to the water until the moment when the needle of the Vica device was lowered low after immersion into the dough for the first time does not reach the surface of the plate, and the end of the setting is when it sinks to a depth of no more than $1 \mathrm{~mm}$.

Water absorption of gypsum was determined on pre-dried to constant weight samplesbeams (Fig. 3). Samples were weighed, placed in a mold, filled up to half with water. After 2 hours, they were completely filled with water and kept for another 2 hours. Then the gypsum samples were removed and reweighed.

Structural peculiarities of the gypsum composites with basalt dust by a method of electronic microscopy were defined. 


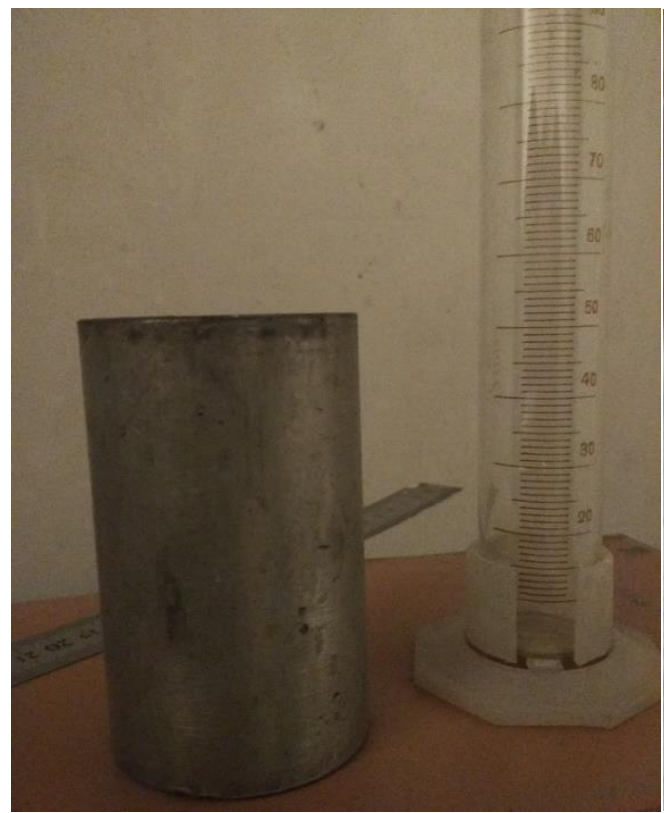

Fig. 1. Definition of water requirements.

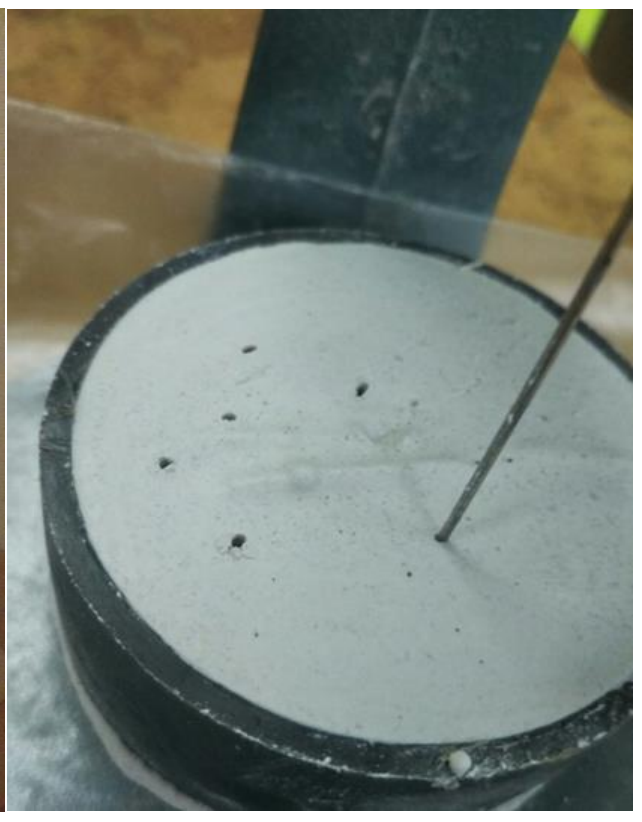

Fig. 2. Definition of setting time.

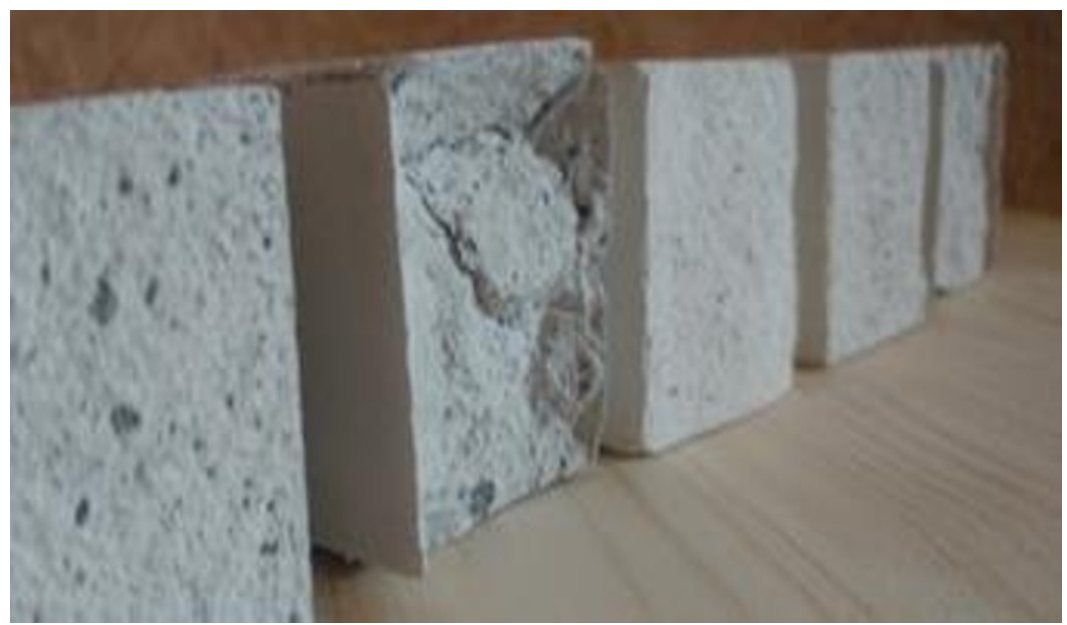

Fig. 3. Samples of gypsum stone before water absorption tests.

The results of the study of the effect of basalt dust on the normal consistency of the gypsum paste showed that, on average, the introduction of each subsequent $1 \%$ of basalt dust into the composition of the gypsum binder increases the value of water requirements by $0.75 \%$ (Fig. 4). This suggests the water-raising effect of basalt dust. 


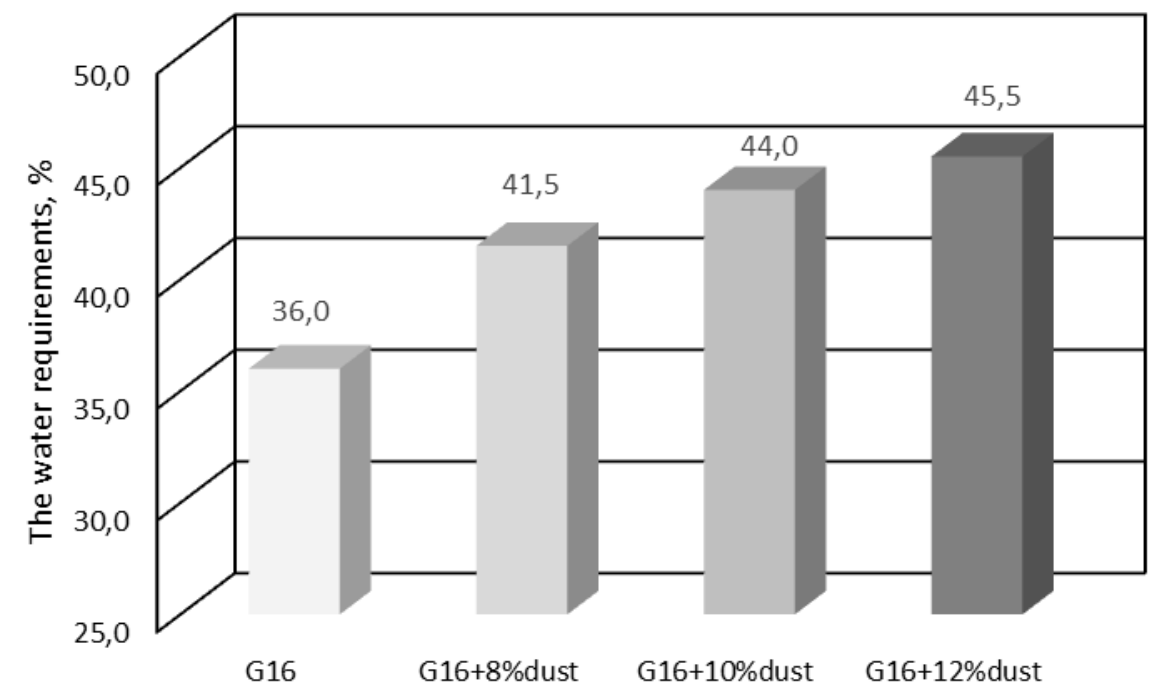

Fig. 4. Influence of basalt dust on water requirements of gypsum paste.

It is established that the basalt additive is reflected in the setting time. The Start and end of setting of the gypsum binder decreases with the introduction of basalt dust with the composition, which suggests its possible influence on the hydration processes of the gypsum binder, by increasing the solubility of the hemihydrate in water (Table 1). The setting period is also shortened.

Table 1. The effect of the amount of basalt dust for setting plaster binder.

\begin{tabular}{|c|c|c|}
\hline $\begin{array}{c}\text { Dust content, \% by } \\
\text { weight of binder }\end{array}$ & Start setting, min & $\begin{array}{c}\text { End of setting, } \\
\text { min }\end{array}$ \\
\hline 8 & 11 & 12 \\
\hline 10 & 10 & 11 \\
\hline 12 & 9 & 10 \\
\hline
\end{tabular}

The content of basalt dust in the composition of the gypsum paste contributes to the increase in water absorption of the gypsum stone obtained (Fig. 5). Introduction to gypsum binder dust in the range from 8 to $12 \%$ of the mass of the binder increases the water absorption of the resulting stone by $6 \%$, which indicates the negative effect of dust on the water resistance of the obtained gypsum products. 


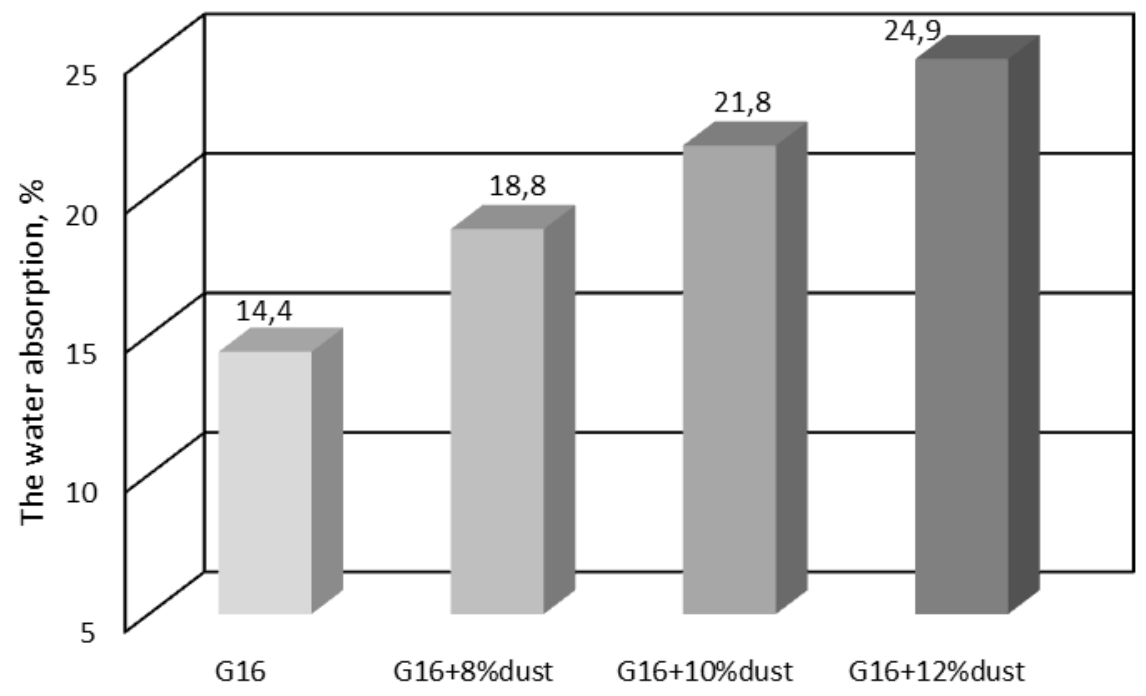

Fig. 5. Influence of basalt dust on water absorption of gypsum stone.

The introduction of basalt waste contributes to a change in the morphology of the crystals and the entire structure of the stone. The modification is reflected in the habit of the crystals (Fig.6).

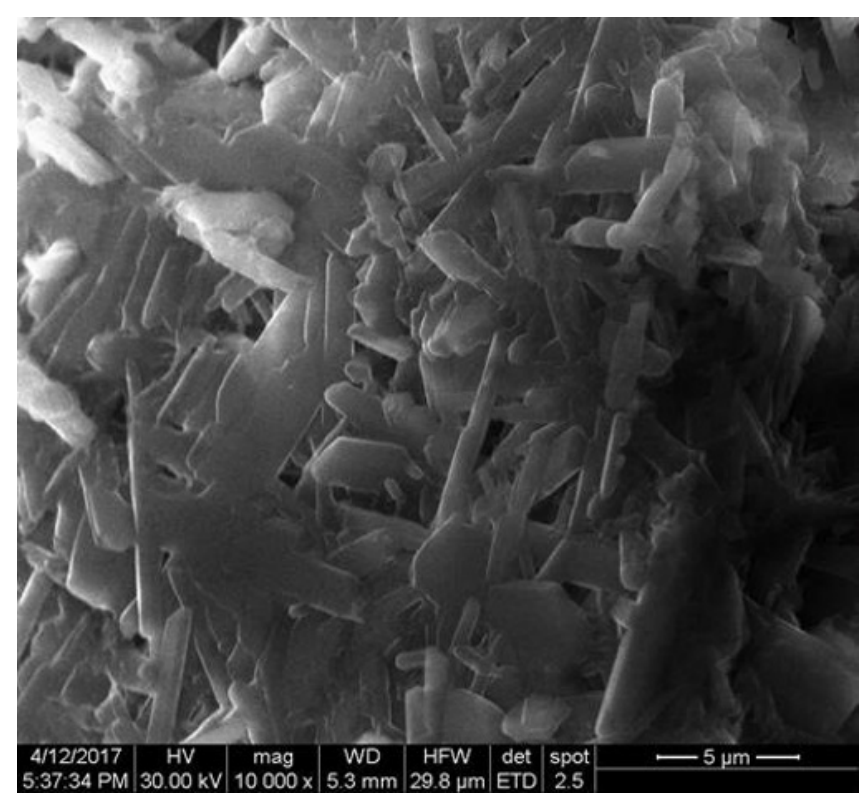

Fig. 6. Modified gypsum structure with basalt dust additive.

Thus, in the course of the research it was revealed that basalt dust can be used as an additive in the composition of raw mixtures based on calcium sulfate hemihydrate. Basalt dust has a water-raising effect. This can be positively used in the process.

The setting time of the gypsum binder decreases with the introduction of basalt dust into its composition. The shortening of the setting period is explained by the effect of aluminates, apparently. 
The content of basalt dust in the composition of the gypsum composite contributes to an increase in water absorption of the gypsum stone produced. This is also due to the chemical composition of the dust.

Taking into account the results obtained, it is advisable to continue research in order to optimize the composition of gypsum composites modified with basalt dust by selecting and introducing effective chemical additives to the composition.

\section{References}

1. I International basalt forum: assessment of realities and opportunities of the basalt industry 5-6, 117-119 (2016)

2. N. E Ablesimov, YU. G. Malova, Scientific review. Tech. science. 6, 5-9 (2016)

3. V. Petropavlovskaya, A. Buryanov, T. Novichenkova, K. Petropavlovskii Self-Hardening of a Gypsum (2015)

4. V. S. Lesovik, G. G. Ilinskaya, Basalt fiber as a reinforcing material for dry construction mixtures (2010)

5. D. YU. Aleksandrov, Basic and applied researches of young scientists 17-20 (2017)

6. L. V. Pagina, D. A. Dadunashvili, Master`s Journal 2, 391-396 (2016)

7. V. Kmecova, Z. Stefunkova Civil Engineering and Architecture Research 4, 260-267 (2014)

8. S. Uneic, V. Kmecova, Procedia Engineering 68, 51-56 (2013)

9. N. A. Eroshkina, M. A. Korovkin, Construction, science and education 1(1), 25-28 (2015)

10. YU. V. Sizov, D. G. Abramov, Actual problems of life safety and ecology, 309-312 (2017)

11. V. S. Izotov, R. Kh. Mukhametrakhimov, A. R. Galautdinov Construction Materials 5, 20-23 (2015)

12. V. B. Petropavlovskaya, T. B. Novichenkova, A. F. Buryanov, V. N. Soloviev, K. S. Petropavlovskii Bulletin of Moscow state university of civil engineering, 12 (111), 1392-1398 (2017)

13. V. B. Petropavlovskaya, T. B. Novichenkova, K. S. Petropavlovskii, A. F. Buryanov, MATEC Web of Conferences ser. "International Science Conference SPbWOSCE-2017 "Business Technologies for Sustainable Urban Development"" 03009 (2018)

14. V. B. Petropavlovskaya, T. B. Novichenkova, K. S. Petropavlovskii, A. F. Buryanov, Building materials, equipment, technologies of the XXI century 1(192) 15-17 (2015)

15. V. B. Petropavlovskaya, V. V. Belov, T. B. Novichenkova Low-power gypsum building composites (2014) 